\title{
Emerging from the darkness and stepping into the light: I mplementing an understanding of the experience of nurse addiction into nursing education
}

\author{
Karen Lee Burton \\ Nightingale College, Ogden, USA. \\ Correspondence: Karen Lee Burton. Address: 4155 Harrison Blvd. \#100; Ogden, UT 84403, USA. Email: \\ kburton@nightingale.edu \\ Received: December 16, 2013 Accepted: January 16, $2014 \quad$ Online Published: February 18, 2014 \\ DOI : 10.5430/jnep.v4n4p151 \\ URL: http://dx.doi.org/10.5430/jnep.v4n4p151
}

\begin{abstract}
Abuse of drugs and alcohol occurs across all cultures, generations, and occupations, including nursing. Nurse addiction is a topic of serious concern that is often dismissed or ignored in the profession. Impaired nurses can become dysfunctional in their ability to provide safe, appropriate patient care. This qualitative study explored the lived experience of nurses who have been addicted to substances. Knowledge of this phenomenon may help guide nurses, nurse educators, and nursing students more accurately understand the reality of substance use disorder in the profession. In this qualitative study, 14 nurse addicts in recovery were interviewed about their experiences and risk perceptions. Analysis was conducted through coding, the identification of meanings and themes, and the use of qualitative research software. Five themes were identified from the study: (a) Fear was a significant part of the experience of being a nurse who was addicted; (b) Shame and guilt were felt by nurses who were addicted; (c) Poor coping: Addicted nurses reported having underdeveloped coping skills; (d) Control: Addicted nurses felt an increased need to control their environments; and (e) A core problem inherent in nurses who were addicted was a belief that addiction would never happen to them. Discussion of the five identified themes was followed by a discussion about addiction risk, prevention, and suggestions for application in nursing education. Participants discussed their experience with nurse addiction in their nursing education experiences and offered suggestions for more effective ways to teach the subject in nursing school. Implications for nursing education were then discussed, including using peer educators, namely, recovering nurse addicts, as teachers of this subject. Implications for nurses globally are presented. Finally, the overall theme identified was that addicted nurses often felt misunderstood and judged, and they desired to be accepted among others in the profession.
\end{abstract}

\section{Key words}

Addiction, Substance use disorder, Nurses, Nursing education, Risk, Experience

\section{I ntroduction}

A gap in the literature exists related to nurses who are suffering from addiction, and how they perceive their lived experience. This phenomenon has largely been overlooked from a qualitative standpoint, yet continues to be a serious 
issue in the profession because of the potential risk posed to patients being cared for by impaired nurses. Nurses need to understand the reality and experience of nurse addiction in order to recognize warning signs in colleagues as well as in themselves. Addiction rates among nurses are estimated to mirror that of the general population, which stands at about $10 \%{ }^{[1]}$. Effective methods of educating nurses about nurse addiction has largely gone unexplored as well, though a need definitely exists to change the way this sensitive subject is approached. No similar studies addressing this issue from a qualitative standpoint could be found. The negative consequences of drug abuse and alcoholism do not only affect the addicts themselves, but also their families, friends, employers, and other associates. Substance abuse almost always causes problems in thinking clearly, remembering, and in paying attention and staying focused, so it is especially important for nurses to avoid this pitfall. Understanding the lived experience of nurses who are addicted may help nurses identify their own risk factors for addiction before entering the workforce. It may also help students and nurses better recognize problems in their addicted co-workers. Nurses in all specialties need to have a more realistic and accurate picture of what it will be like to be a nurse and have access to addicting drugs, and how they must know how to work with these drugs appropriately. Understanding this phenomenon could help nurses globally in dealing with and understanding the issue of nurse addiction.

In nurses, substance abuse not only decreases productivity in the workplace but presents a risk to the patients being cared for. Increased patient risk and decreased nurse productivity places a heavy burden on employers. Nurse addicts are a unique population that have been explored from punitive and treatment perspectives, but have rarely been explored from an experiential qualitative standpoint. A more accurate knowledge and understanding of this population of nurses is needed in order to more effectively educate nursing students about this issue while they are still in school. The substance use patterns of nurses and their responses to addiction are understudied phenomena, especially the relationship of substance use to the specific nursing work environment. The purpose of the study presented in this article was to investigate, explore, understand, and describe the lived experience of nurses who are addicted to drugs and/or alcohol. The research question that served as the foundation for the study was the following: What is the lived experience of nurses who are addicted, and how do they perceive their risk for addiction?

\section{Background/ literature}

Nursing schools have been and continue to be challenged to integrate substance abuse and addiction content into both their undergraduate and graduate curricula. It has been proposed that for many nurses, substance abuse begins while attending nursing school ${ }^{[2]}$. Governing nursing education bodies have issued challenges to pay more attention to this issue ${ }^{[3]}$. Efforts to improve education on this topic cannot be accomplished without special attention being given to understanding the experiences and perceptions nurses struggling with addiction have. Nurses who have lived the experience are able to share their knowledge and unique perspectives to further the knowledge of this often ignored or masked topic. Alcohol and drug addiction are primary, chronic, progressive, and often fatal health concerns ${ }^{[4]}$. Substance abuse among nurses has existed for at least 150 years, with intoxication on the job existing even back in the $19^{\text {th }}$ century when Florence Nightingale began her work. Many nurses in the "Dark Period of Nursing" (1500-1860) were often illiterate, rough and inconsiderate, and often times alcoholic ${ }^{[5]}$. Nurses were drawn from prisoners, prostitutes, and criminals who scrubbed, cleaned, and worked long hours, so the use of substances in nursing can be traced back far into the profession's history. Today, for each nurse who admits to having a substance abuse problem, many other impaired nurses most likely remain unidentified and continue to practice as nurses. Research has shown that nurses appear to be at similar risk for substance use disorders as the general public, but because of nurses' access to narcotics, their patterns of drug abuse are unique ${ }^{[6]}$. Chemical dependency undermines a nurse's physical, psychological, social, and professional functioning, and needs to be addressed from a prevention and health promotion standpoint as early as nursing school ${ }^{[7]}$. Nurse addiction also causes strain to individuals and increased turnover in the nurse workforce ${ }^{[8]}$.

Very little has been done to explore the actual feelings and lived experiences of addicted nurses in qualitative research studies. Nurses and nurse educators need to have a better understanding of what it is like to be a nurse addict, in order to better assist and teach other nurses in the profession. A greater understanding of this phenomenon will also assist 
practicing nurses in working with their peers who may struggle with drug addiction. It will also help nurses understand and identify risks they themselves may have related to becoming addicted to narcotics. Nurses need to understand the phenomenon of nurse drug addiction in order for new nurses and students to realize the full impact of this problem, who can then take it into the workplaces with them. Nurses who have lived the experience are able to share their knowledge and unique perspectives to further the knowledge of this often ignored or masked topic.

As a start for the research study, a review of the existing literature was done to determine and document the need for this qualitative study. Every step of the literature review and eventual research study were checked by two additional doctoral-level research advisors, in an effort to keep researcher bias at a minimum. In an effort to understand what literature exists on the topic of nurse addiction, a preliminary review of the literature was conducted. Studies exploring lived experience of addicts and other aspects of the phenomenon were sought out. A second review of the literature was conducted after study data were analyzed, in an effort to substantiate the qualitative results discovered during the process of data analysis. In the initial review, several quantitative studies were discovered, however qualitative studies were very difficult to locate. No other qualitative studies on nurse addiction from the perspectives of the nurses could be found. After study data were analyzed, the subsequent literature review was extensive and is integrated throughout the results and implications sections of this study.

\section{Methods}

A phenomenological method of investigation was used in this qualitative study. This design was chosen in order to achieve the purpose and aims of the study. The approach for this research design was built upon Husserl's phenomenological philosophy, which has a purpose of studying the "lifeworld in its appearing" ${ }^{99}$. This 'lifeworld' consists of all the immediate, self-evident and given experiences, activities, and contacts that a person has with reality. In the report of findings in this study, descriptions are provided describing what it is like to experience the phenomenon of nurse addiction. These descriptions are based on what the nurses have expressed and communicated about it in their interviews-both verbally and non-verbally.

Recruitment of subjects took place with the cooperation of the state's "diversion" program, who distributed fliers with the researcher's contact information and description of the study to all of the nurses currently in their program. Fliers asking for participants were also distributed at "Professionals in Recovery" support group meetings, and then once some participants were identified, they referred other potential participants. This is often called "snowball" or "network" sampling ${ }^{[10]}$. After recruitment efforts were made and participants were identified, a purposive sample of 14 nurses experiencing addiction became the study sample. Sample size was determined when saturation of data became apparent. In the end, of the 14 study participants, 9 were female and 5 were male nurses. One was Hispanic and the other 13 were Caucasian — which closely mirrors the state demographics where the study took place. These nurses all had different lengths of time in recovery as well as different amounts of time as practicing nurses. Most were addicted to more than one substance, with opiates being the most common addiction. Only first names were obtained by the researcher, and then first names were changed for the study write-up in order to maintain confidentiality. In order to protect human subjects, International Review Board (IRB) approval was obtained before any data was collected.

Each interview started with the consent being given by participants on a non-signature consent form. Verbal consent was recorded with the interviews in order to protect confidentiality, so no names were recorded anywhere. Once consent was given, each participant was given a demographic form to fill out. Demographic information gathered included years practicing as a nurse, amount of time during which drugs or alcohol were abused, amount of time in recovery, nursing specialty, and other basic demographic information such as age, gender, and ethnicity. Once the demographic form was filled out by each participant, an interview was conducted, recorded, and eventually transcribed verbatim. An interview guide created by the researcher was used as a guide of questions for each interview. A semi-structured interview method was employed, which includes the use of more and less structured questions than what is on the interview guide ${ }^{[10]}$. The 
interviews were conducted individually as scheduled by the researcher and the participants, and lasted between 30 and 60 minutes. Besides interviewing, another method implemented for data collection in this study was observation. Notes were made as participants were observed by the researcher during the interview process.

Once interviews were transcribed, analysis commenced. Transcripts were read and re-read, and then manually coded by the researcher using a color coding system. Key phrases and ideas were coded and meanings were formulated. From each transcript, significant phrases or sentences that pertained directly to the lived experiences of addicted nurses were identified. Risk perceptions were considered, as well as whether or not the nurse addicts felt they were at greater risk for addiction by virtue of being nurses. Further questions related to their experiences related to education about nurse addiction were asked, as well as what they thought would be the most effective way to teach this subject in nursing schools. Participants were asked if they felt anything would have been helpful in preventing the addictions from occurring. In addition to manual coding, qualitative data analysis using software called NVivo® was used for organizing and analyzing data. Transcripts were imported into the software program and organized accordingly. Within NVivo® each interview question was "autocoded" in order to look at all fourteen respondents' answers to each individual interview question on the interview guide. Text search queries were run within the software program and word frequency queries were explored there. Themes that emerged from the computer analysis were compared to what emerged from the manual coding. Meanings were then formulated from the significant statements and phrases in both the manual coding and the computer results. These formulated meanings were then clustered into idea groups allowing for the emergence of themes common to all of the participants' transcripts. Codes were categorized and final themes were identified. Five themes were identified throughout the data analysis process. Discussion and implications resulted from the 5 themes and from the literature review which followed. An overall theme in the study resulted from the five themes and discussion items that were identified. The data analysis in this study was primarily inductive and comparative.

Validity and reliability were pursued and achieved by certain measures employed by the researcher. One measure that had to be employed in this study to ensure reliability and validity was the bridling of the researcher from her own experiences and thoughts on the subject being researched. In an effort to ensure the interviewer did not influence the contents of the participants' descriptions of their experiences, an interview guide was used and reviewed by other nurse researchers prior to the initiation of interviews. The interview guide served as a foundation for all of the interviews, though additional questions were added based on responses given by individual participants. Design flexibility was needed in the qualitative inquiry in order to allow the researcher to pursue inquiries on new topics or questions that emerged as a result of the questions asked from the interview guide. The researcher did not offer personal opinions or ideas about the phenomenon during the interviews but acted only as a listener and questioner and recorded the thoughts and statements of the person being interviewed. Every effort was made to ensure the descriptions given by participants truly reflected their actual experience $^{[11]}$.

\section{Results}

Despite differences in age, specialty area, years addicted, years in recovery, and other characterizing factors, some common ideas and findings emerged through the process of data analysis. As a result of data analysis efforts, 5 themes have emerged from the data. The five themes are as follows: 1) Fear is a significant part of the experience of being a nurse who is addicted; 2) Shame and guilt are felt by nurses who are addicted; 3) Poor coping: addicted nurses report having underdeveloped coping skills; 4) Addicted nurses feel an increased need to control their environments; and 5) A core problem inherent in nurses who are addicted is a belief that addiction would never happen to them.

Only 6 of the 14 participants in this study stated they received some type of formal education about nurse addiction in nursing school. Eight of them do not remember learning anything about it at all in school. Of the six that reported learning about it, 5 said what they were presented was ineffective or useless. Overall, the subject seems to be missing from educational programs, and if it is there, improvements in how and what is taught might be helpful. 
Peer support was found to be a major factor for recovering addicts in getting healthy and in overcoming their addictions. Though not identified as one of the "themes" of this study related to lived experience of nurses who are addicted, a very significant and unexpected finding emerged from these interviews related to how recovering nurses view the power of peer addict support.

\section{Discussion}

\section{Theme 1: Fear is a significant part of the experience of being a nurse who is addicted}

A common thread through each of the interviews with recovering nurse addicts was the presence of fear-both during active addiction as well as while in recovery. Fear is not always easy to define. It may be something innate or learned and it can be very complex to understand. Fear manifests itself in many ways throughout addiction. Sometimes fear is the precursor to drug abuse. It almost always comes as a result of drug abuse while the addict is engaging in his or her addiction. Sometimes it is worry after the drug abuse has stopped. Fear is undeniably a survival mechanism in some instances, but can also psychologically immobilize people who are chronically afraid. Nurses who are addicted experience a lot of fear. Their fears are legitimate and clearly cause significant anxiety for them. The words 'fear' as well as the synonyms--worry, afraid, scared, anxiety, care, and concern--were frequently used throughout the interviews. For several nurses, fear of being caught while in active addiction was a major concern for them. One nurse said:

...early on I didn’t have any feelings of fear but toward the end of my active use I felt like I was constantly...flying under the radar, but then again I always thought, 'when are they going to come ask me about my possible use?...'Who’s noticed anything?'. Really when it comes down to it I always wondered if maybe that was going to be my last day at work. I feared for my license but I feared more for the inability to provide for my family if I did lose my job.

Along with fear of being caught, this nurse said he worried about losing his job or his nursing license. He worried about not being able to provide for his family. These are all big concerns. Another nurse expressed similar fears:

I was definitely worried that I'd get caught. Because if I made a big enough mistake at any time they could turn around and say let's go down to the ER and have you pee in a cup for us...so yeah I definitely had fear. Fear, shame, guilt was running my boat. I wasn’t in denial, I’ll tell you that. I was well aware of my addiction.

In order to better understand why humans experience fear, a research study was conducted by Nevin Mert in 2012. His study attempted to describe fear in terms of developmental, humanistic, behaviorist, and social aspects ${ }^{[12]}$. All of the participants experienced significant fear in one way or another. When the literature was explored further related to fear and addiction, it was discovered that not only do fear and addiction appear to be psychologically related, they also have been shown to possess a physiological relationship. One group of researchers report evidence that both addiction and fear overlap in the prefrontal cortex of the brain; they are physiologically related ${ }^{[13]}$. Both fear and drug seeking are conditioned responses that can lead to maladaptive behavior when expressed inappropriately.

Other research studies were found which also supported the idea of fear and addiction being linked physiologically ${ }^{[14-16]}$. Fear has been shown to be physiologically related to addiction in the prefrontal and orbitofrontal cortexes of the brain, but also has many psychological components in the addicted person. All of the fourteen nurses in this study experienced fear in one form or another, and many continue to experience fear in recovery. They fear relapse, being judged or rejected by others, or being discovered as an addict in recovery. 


\section{Theme 2: Shame and guilt are felt by nurses who are addicted}

Besides fear, all of the participants in this study at some point made mention of feeling ashamed, guilty, or embarrassed as a result of their drug abuse and addictions. These feelings of guilt and shame often came as a result of personal morals and values being violated, from self-condemnation, from having to deal with people who knew what had happened treated them differently as a result, and from several other sources or experiences. All of the nurses interviewed admitted to feeling ashamed in some way or another-whether it was ashamed of being an addict, ashamed from being discovered, or ashamed to have taken medications from their employers. Many felt ashamed they could not stop the drug use on their own. One nurse made the following statement relative to his experience of being an addict while using:

Once I realized the problem, the guilt involved...not only knowing that hey I've got a problem, but diverting medication that didn't belong to me...there's a lot of both moral and ethical...I had the guilt more on the days that I'd used rather than days not, but it was always there. Shame and even feelings of depression...sadness. I mean, I loved my job, but then again I hated it at the same time because of what I'd become.

Like him, a different nurse questioned how this could have happened to her:

I felt bad, you know. I felt guilty. I felt very guilty. I never took anything from anybody that was in pain or anything like that. I would never do that. I'm a real caregiving person and I love to help people. And I could see that the other nurses around me were working, but in my mind I'm thinking, 'they can't be all straight'... I always wondered, am I the only one? You know, why is this happening to me? ...but I did feel guilty. And I didn’t want to shame the unit, and I didn't want to put shame on the fact that I was a nurse either.

Another nurse also expressed feelings of shame and guilt when asked what the overall experience of being a nurse who is addicted is like. She worked in a jail and had been interacting with inmates who were addicted on a regular basis. She had even admitted to thinking her addicted patients were weak, so realizing she herself was addicted was very shameful:

There was a tremendous shame because I was supposed to be helping other people with their medical problems and I couldn’t even help myself with my own. And especially because I was working with law enforcement in that point in time and there was an extra layer of holy crap I just fell into something that I despise.

The literature was once again investigated related to guilt and shame in addiction. In a paper aimed to explore the existential aspects of living with addiction, one researcher describes a study she conducted where guilt is identified as one of the themes presented as challenges of conflict that must be met by people recovering from addiction ${ }^{[17]}$. This study did not focus on nurses specifically, but talked of guilt and shame in addiction. Whether nurses or not, addicted individuals seem to experience significant feelings of shame and guilt both while using the substances as well as after use is stopped. Unique dimensions come with being a nurse who is addicted, though, as these nurses have to deal with the ethical implications of taking medications from work or from patients. They also deal with shame in realizing they compromised their professional role, and that they often have compromised relationships of trust—both with employers and sometimes patients, as well as dealing with their families and legal entities. Shame and guilt undeniably often accompany nurses who are addicted.

\section{Theme 3: Poor coping: Addicted nurses report having underdeveloped coping skills}

One of the questions in this research study was to find out whether or not nurses in recovery consider themselves to have been at risk for addiction just by virtue of being a nurse. Risk perceptions discovered in general will be discussed at length in Theme 5 of this study; however, an unanticipated theme emerged from a response to this question by one of the participants. When one nurse was asked whether he thought people were at risk for addiction by virtue of being nurses, he said: 
I don't think they [are], no. It becomes for me, it all depends on how you are able to cope. Coping mechanisms and your genetics. I don't think being a nurse puts you at higher risk. But I guess if you are always being put in places of stressful situation if you haven’t learned those coping mechanisms I can see how...

Later in his interview, when asked how he felt the subject of nurse addiction could most effectively be taught in nursing education, the same nurse said:

[By] learning how to deal with their own behavior. That's the best way. If you're stressed and you're going crazy you have to let people in on that. You have to say hey I'm stressed and going crazy. You have to share these thoughts that are going on in your head and take action. Learn how to apply the nursing process to yourself. I mean we apply it all the time to our clients; we have to turn around and assess ourselves.

Learn how to cope, and coping with yourself is the biggest key...because drinking and using is just the tip of our disease. We have to go back to where it's festering, because it's guilt and shame that I can't handle anymore or if it's because of my childhood or because of the high stress at work or if it is because of the pills while I'm at work, all you got to do is go talk about it to somebody and they'll help you deal with it.

This nurse's very insightful response to the best way nursing students need to learn about addiction by looking at the root problems underneath addiction has proven to be very profound indeed. After thoroughly studying his interview, the researcher went back over the other transcripts again to see whether or not ineffective coping was something that any of the other nurses had mentioned. In fact, none of them had mentioned it in those words, but all had described their addictive behaviors that had occurred as a result of ineffective coping! When asked if anything could have prevented her addiction, one of the participants responded:

It would have had to go back even farther; I would have had to have just known better coping mechanisms in life and just learned how to be honest despite any consequences. Because I always learned how to lie to avoid consequences and that's what using is. We just keep lying to avoid the consequences of admitting that we're using. I developed poor coping skills early on as a child.

Several viewpoints on the ontology and epistemology of the concept of coping exist in the literature for nursing as well as in other disciplines. One group of researchers defined coping as "an essential element in being resilient in the face of physical disability and stress" ${ }^{[18]}$. Coping requires candid and forthright facing up to things that often cause fear in individuals. It is a way for people to look at themselves and be honest, with the willingness and the strength to acknowledge the things that may be wrong in themselves.

Healthy coping quite often does not take place in the lives of people who are addicted, and this study on nurse addiction was no different. Time after time, when these addicts were asked to describe how their addictions began, stressful experiences or difficult situations almost always precluded the initiation of the substance abuse. They did not know how to effectively cope. The nurses in this study often exhibited poor coping skills.

\section{Theme 4: Addicted nurses feel an increased need to control their environments}

Most addicts and alcoholics often experience some form of denial. The term "denial" refers to the process by which addicts pretend (or actually believe) they do not have an addiction, when in fact they really do. People in denial do not think their behavior is problematic, when in fact it is. Denial—both in their own risk perceptions of addiction and in their actual reality of being addicts or alcoholics - was strong in this study on nurse addicts, but one aspect of that denial really stood out. That aspect of denial which has emerged as the fourth theme is a false sense of control—which in turn contributes to an overall state of denial in these nurses. All 14 nurses referred at some point to how their substance use started small or 
occurred infrequently in the beginning. Of the 14 nurses, 11 of them directly commented on how they felt they could control their use in the beginning, or quit whenever they wanted to, so they did not feel they were addicted. The other 3 did not directly say they felt they were in control, but statements were made which inferred that conclusion. At the time the control was lost, they did not realize it, and they begin trying to control their drug use in an effort to convince themselves that they were still okay. Ironically, when they were most out of control, they fought the hardest to control everything they could. They attempted to control their substance use-amounts, times of the day they would use, types of drugs they would and would not use, and so forth. Some of that false sense of control came because of their education and training as nurses - they felt they were immune to addiction since they knew everything about the medications they were using and they knew when it was needed and when it was not. One participant stated:

I'm a nurse, I know how to do it and not get caught and I'll control it and I'm not going to use on days that I work and I'm not going to use while I'm working, and I'm not going to get addicted because I'm smart. I'm a college girl...And within a year and a half I was shooting up a hundred dollars a day. Initially when I first started using I didn't use while I was working. I waited till I was off work or on my days off because I was smart and a college student...I'm going to control this. So I would do it on pay days, on days off, and then it just kind of progressed from there.

Another nurse commented that she started wanting to take all of the extra shifts, and when she worked; she offered to take the hardest patients because they would be the ones who needed the most drugs. The need to control the situation and the drug use led many of the nurses studied to excessive working and taking on of extra shifts in order to have the access they needed to the drugs. Yet another participant also commented on this feeling of being in control:

...being around them [drugs] and feeling a superior sense of control over the drugs. We know how they work, we know how the dosaging works, so we can use safely. It's a dangerous mix of knowledge thinking we had power of it and we can use safely and not knowing we are at risk for it because that wasn't discussed in nursing school.

This theme of needing to control their use (and everything else around them at times) was a pervasive thread that went through these nurses' recollections of their experiences. It was an aspect of denial that really had not been considered by the researcher before this study was done, so once again the literature was searched to see if any evidence existed about this phenomenon with nurses or any other group of addicts. As far back as 1959, in his paper or human motivation, R.W. White submitted the idea that the need to control the environment is most central to the human species. Another study which looked at need for control was conducted on a sample of people experiencing eating disorders. This study showed that the need to control was definitely a factor exhibited with the compulsive behaviors of people with anorexia nervosa ${ }^{[19]}$.

\section{Theme 5: A core problem inherent in nurses who are addicted is a belief that addiction would never happen to them}

Risk is a situation or event where something of human value (including humans themselves) is at stake and where the outcome is uncertain ${ }^{[20]}$. Outcomes, usually negative when related to risk, are also uncertain and vary in severity. One of the purposes of the study at hand on nurse addiction was to find out how recovering nurses perceived their own risk for addiction. A clear finding in all of the interviews was the pre-addiction belief of theses nurses that becoming addicted would never happen to them - whether they became addicted before becoming nurses or after becoming nurses. Eleven of the fourteen stated they never considered themselves to be at risk for addiction when asked the question, but the other three agreed at some other point in the interviews that they never thought addiction would happen to them. It is significant that not a single one of these nurses ever considered themselves to be at risk for becoming addicts. When asked if she felt she was at risk for addiction, one nurse said: 
Not at all. In fact I always have been more of the opposite extreme. I had my children natural, all but one without an epidural. I was against medication when I had surgery... even though I was a nurse and administered medications as needed; when it came to myself I preferred more natural alternatives to everything. When I had surgery in the past I used ice packs and avoided the narcotics...I was the kind of person who didn't even take home prescriptions after surgery or after child birth. I wasn't a drinker even when I turned 21. My husband wanted to go and hang out for fun at a bar because I was old enough, but I still never went to bars, never! I was just really against that kind of lifestyle for myself. So not at all would I have considered myself at risk to become an addict.

After talking to this nurse about her family history of alcoholism, the researcher went back and reviewed the other transcripts again and discovered that out of the 11 nurses who never considered themselves to be at risk for addiction, 8 of them commented on having a strong family history of addiction or alcoholism! It is baffling to comprehend how these nurses, with their education about addiction and their knowledge of strong genetic predispositions for addiction, could truly not perceive themselves to be at risk...but they did not.

Understanding the reality and feelings of addiction in nurses is vital for all nurses and nurse educators. The five themes identified in this research study represent in large part the lived experience of nurses who are addicted. In addition to lived experience, risk perceptions were explored. After the participants were asked about whether or not they perceived themselves to be at risk for addiction, they were then asked whether or not they felt people in general who became nurses were more at risk for addiction just by virtue of being nurses. Some literature has suggested that the risk for addiction is an “occupational risk" for nurses ${ }^{[21]}$. Whether or not nurses are at greater risk for addiction by virtue of being nurses may not be answerable at this point, but one finding about risk in this study was: most nurses do not consider themselves to be at risk for addiction before it happens. This is where the experience of these nurses may become extremely beneficial to nursing students. It is assumed, since none of these nurses ever thought they would turn out to be addicts, that nursing students probably also feel they will not be one of "those" nurses that uses or abuses narcotics. Perhaps if they realize that most nurse addicts also felt that way at one time, they will think twice about taking their sobriety and risk for granted.

\section{Nurse addiction in nurse education}

As mentioned previously, it appears there is a deficit in the way the subject of nurse addiction is being taught in nursing school. One nurse from the study said, “I think the right thing is definitely to have more education out there. I don't think that it's something that we can ignore. I think it would make us better practitioners to have more education ahead of time...more able to recognize addiction and treat it and have more compassion.”

Other types of schools and disciplines have been teaching about addiction prevention for their own students for years. As early as elementary school, young students are educated about addiction and how it manifests itself. Elementary, junior high and high school age students learn the importance of saying "no" to drugs, and what to avoid. They learn how the types of drugs they may be exposed to will affect them should they choose to use them, as well as how to recognize drug abuse in others. The Center for Disease Control (CDC) has provided guidelines to prevent tobacco use and addiction in school children, and frequently tests the effectiveness of the education that is taking place ${ }^{[22-24]}$. Clients in addiction recovery treatment centers even learn how to empower themselves against using drugs and alcohol, and how to find resources to help them if they should find themselves at risk ${ }^{[25]}$. If school children and adolescents, recovering addicts, and college students in many general education settings learn about addiction and how it relates to themselves personally, it makes sense for nursing students to learn about it relative to their own risks and not just relative to the patients they will be taking care of. If nursing students only learn about addiction as it relates to people they will be taking care of, the problem of nurse addiction will continue to creep up on unsuspecting nurses as it has done in many of the participants in this study. 


\section{Recovering nurse addicts as peer teachers}

Peer support appeared to be a major factor for recovering addicts in getting healthy and in overcoming their addictions. The finding came about primarily through a question asked in the interviews relating to what the interviewees felt would be the most effective way to teach about nurse addiction in nursing school. What they said was so powerful, and enough of them said it that it really cannot be overlooked. Without any leading questions or coaching from the researcher, 10 out of the 14 participants said the thing they felt would be most effective in teaching this subject to nursing students would be to have a nurse or nurses that have been through addiction come and talk to the students about it. Peer education was their answer-and was something that could not be found anywhere in nursing education literature. A few of the informants commented that probably nothing would have prevented them from becoming addicted unless they had been able to see an actual nurse who had experienced come and talk about it. The responses were so profound to the researcher that many of them will be shared here. One nurse who had worked as a nurse for several years before becoming addicted, never partied in high school or college, grew up in a religious family, and was a mother of 5 children said this:

Absolutely the most effective way would be to have nurses like me actually in the classroom. Nurses that are willing to be open about their addiction, which most of us who have gone through addiction recovery are. If we are in truly healthy recovery holding ourselves accountable for what we've done, and being honest about what we've done, then those are the ones that aren't going to be afraid to go in front of a classroom and talk. You know, we're not in hiding because it is what it is. But to see like a nurse like me...someone who normally you'd probably look at and never guess, or someone you've talked to and never ever guessed that they have done the things that I have done to support my addiction, I think it would be a real eye opener to show these people that it can happen to anyone.

I think if it's just being taught by nurses from a book who've never actually experienced it, the message may not get across, or may not leave a mark in their mind for a time down the road where they're practicing and maybe thinking about it too. We need to tell them something they're going to remember because it's their lives. I mean, nursing now is a personal thing. It isn't learning how to change a catheter...it's not a nursing skill. I mean, you know, there are these people who as a teenage have smoked pot, they've struggled with this, they've struggled with that, they had a rough upbringing around it... just kind of the people who you predict will end up in prison or whatever for drugs, not people like me who was the exact opposite. I never ever ever drank or used throughout nursing school or as a child.

These statements are so simple, yet so profound-and she is not the only recovering nurse addict who thinks so. If everything that has been talked about up to this point is considered, though, what she is saying makes a lot of sense. Most nurses do not think they will end up becoming addicted. Most are coping just fine for the stage of life they are in during nursing school but have no idea what it will be like 10 or 15 years down the road when they are getting a divorce or a parent dies or a loved one becomes deathly ill—nursing students are not thinking about that when they are in nursing school...but just maybe if they saw someone like the nurse quoted above, who was just like all of them at their age, who was very "normal" and did not look like the stereotypical "drug addict"-maybe that is something they would remember and even internalize. Maybe these students who do not believe addiction will ever happen to them would hear someone like the nurse from this study say, "I never ever thought I would fall into addiction" and realize that it can happen even if you believe it never could. Maybe being exposed to someone like her, paired with education about coping like several nurses suggested would be just what it would take to make a difference in getting this subject internalized and effective in nursing education. When asked what he thought nursing education needed, another nurse, the family nurse practitioner who started abusing opiates as a nurse after an ankle injury, said:

Personally myself I need to feel a connection. I need to see those individuals. I believe devoting at least more than one lecture on the subject is needed, and for myself, having an open panel discussion with recovering nurses or 
recovering healthcare professionals. But more importantly, nurses as part of the educational process would be the best way to get that information to the students...not just something out of a textbook.

Several of the nurses interviewed mentioned that they hoped this study would help other people. Several of them offered to come talk to nursing students if something like that ever became a part of the nursing curriculum. They expressed a sincere desire to have their experiences help others avoid making the same mistakes. Addicts in recovery want to talk about their experiences. Because this recommendation for peer educators by the participants was so prevalent throughout the interviews, the researcher again turned to the literature so see whether this type of education was already taking place or not. No evidence of this happening in nursing education could be found, even though evidence of peer education related to addiction has been shown to be extremely effective in other environments.

The literature had numerous other studies related to peer mentoring in addiction recovery ${ }^{\text {[25-27] }}$. However, after several different efforts to find other research, no evidence of using peer mentors for a preventative teaching standpoint could be found. When the researcher was about ready to give up, a half-page newspaper article was found that was printed in the New York Times in 2002 that reported a group of medical students at Cornell University who had been educated about addiction by actual recovering addicts. The medical students admitted they felt very insecure about dealing with addicted patients because they had very little experience with them. One student said "I thought the only people who got addicted were those who were wealthy with nothing to do or the urban poor" ${ }^{283}$. After hearing the story of one of the treatment center residents, a medical student stated the experience had helped her see those addicted to drugs as real people. "What I heard were people who were using drugs to make the suffering go away, to get lost in the world of drugs", she said. "This experience will stick with me for a long time.”[28]

This newspaper article was the only bit of literature that could be found in which those learning about addiction from recovering addicts were not addicts themselves. The experience was very powerful and made an impression on the medical students-much more so than learning about it from a textbook or a lecture. This idea is the premise for having recovering nurse addicts come and teach non-addicted nursing students about the reality of nurse drug addiction. Nurse addicts in recovery themselves identified this as the way they felt nursing education could change and cause this content to be more effectively understood by nursing students getting ready to enter the workforce.

Practical strategies for reducing drug addiction in nurses must go beyond education with peer educators in nursing school, however. Understanding nurse drug addiction from the standpoint of the addicts themselves can help nurse administrators and managers in addressing the issue in the work field. Leaders having an accurate understanding of this experience will know how to better approach and treat the issue in their own organizations. They could focus on prevention and education for their nurses in a way that may be more meaningful and realistic to the employees. They may recognize the signs of addiction sooner because of their own education related to the subject. Nurses can be instructed to watch for signs in their co-workers that may indicate substance abuse or impairment in their peers.

\section{Overall finding: Nurses in recovery feel misunderstood and judged, and just want to be accepted}

It became very apparent in this study that many recovering addicts feel a lot of self-condemnation and worry about the wreckage that has been left behind by their addictions. Most feel an acute sense of guilt and shame as the try to rebuild their lives. Addicts are extremely hard on themselves, and really need support and encouragement from those around them. The recovering nurses in this study did feel a lot of guilt, shame, and self-condemnation, but they often do not feel that needed support and encouragement from others in this difficult time. The recollections of their experiences in recovery are threaded with feelings of being misunderstood, judged and demoralized. They frequently express a desire to have nonaddicts understand the "disease" and treat them as people with other diseases would be treated. One nurse was able to verbalize this feeling well: 
I think it [would be] a little bit easier if [instead of] just 'oh you're an alcoholic', or 'you're a drug addict', [others] realized this is an actual disease. We're not going to shove people out. It wouldn't make sense if we shoved people out because they're an alcoholic and drug addict and they're stealing things. Let's get them the appropriate help, just like someone that has diabetes, we need to treat them the same. You're not going to be like oh I ate a whole box of donuts, my blood sugar is 5000, let's educate them on the carb count. The same thing--if someone goes out and relapses we don't want to push them out and shove them away. We have to be like, ok, this is part of the process, but why did you drink and use? Where are these stumbling blocks that you obviously didn't have [tools for] in your tool belt? So I guess we have to learn how to do that better because a lot of people don't see; a lot of our clients don’t see it as a disease, they just see it as a psychiatric disorder; they choose it in a sense.

It is interesting that addiction as a disease is often compared to diabetes. In fact, in treatment settings where addicts are being treated and taught about the disease model of addiction, they are often instructed to view their own addictions as a “disease like diabetes", in order to help them better understand the nature of disease processes. Like this nurse alluded to with obesity and sugar intake, if a person chooses not to regulate and control their diabetes by what they do and do not eat, they may experience negative outcomes because of their disease. People with diabetes have to be vigilant in making sure they stay on top of their blood glucose levels, because if they choose not to, they can experience some of the more serious effects of uncontrolled diabetes. They can lose their eyesight or get severe sores in their feet, or a number of other consequences for not controlling their diabetes. Addiction is very similar. It is a progressive disease that if not held in check will cause severe repercussions. Relapse rates for drug-addicted patients have been compared with those suffering from other chronic diseases like diabetes, hypertension, and asthma. Relapse is common and similar across these different medical illnesses (as is adherence to medication). Thus, the NIDA suggests drug addiction should be treated like any other chronic illness, with relapse serving as an indication for renewed or altered intervention ${ }^{[29,30]}$.

With all of this information being taught to the recovering nurses, it is no surprise they often feel misunderstood when everyone outside of recovery rooms is treating them like they have something wrong with them. In reality, most recovering nurse addicts are doing the best they can to rebuild their lives, and just they yearn for acceptance instead of judgment. Most nurses are actually very intelligent and skilled, and want to be seen and accepted for the good things they can do, and not only be labeled as "addicts". One participant stated:

I don't know if it's just nurse addiction, but it's kind of depressing that the wealth of knowledge and experience that are in the meeting rooms of all these nurses that [are] branded as almost worthless because they were addicts--but their abilities and their skills are not diminished by the fact that they had an addiction problem. And that's the kind of pervasive thing that is still going on. Like ok, you were an addict, well that takes the fact that you were a 20 year special [labor \& delivery] nurse or something like that away because you took a couple pills or you had a problem. It doesn't.

Many of the interviews done in this study had an underlying tone of sadness or remorse portrayed by the informants. The nurses were not sad they had addictions_ — or even sad about being caught—-they seemed sad about being "that nurse" who was no longer respected and often judged.

\section{Limitations}

One potential limitation of this study was the sample size of 14 subjects. While appropriate for qualitative inquiry since data saturation was reached, it was still considered a smaller sample size relatively speaking, which may not fully be representative of the larger population of nurse addicts. Using a smaller sample size could make generalization to the larger population more difficult. Another potential limitation was the varying backgrounds of the subjects who were interviewed. Generalizability to all nurse addicts was difficult when not all of the study participants had the same variables involved--i.e., drug of choice, whether or not they were addicted before becoming nurses, and whether they used drugs from work or not. A potential limitation may be that the participants were all recruited from the same place (one state's 
diversion program) or referred by other study participants. Anyone recruited by the diversion program was currently in their licensure probation stage of the process, which would indicate they were newer in recovery. Ideally it would have been good to find nurse addicts in all stages of recovery.

\section{Recommendations for further research}

Recently, pedagogy to help nursing faculty and students meet current societal and professional demands and standards related to substance abuse has been implemented in many nursing, but more needs to be done ${ }^{[31]}$. More qualitative research on this topic would be especially useful, so nurses, nurse educators, and students would have a more accurate understanding of the phenomenon of nurse addiction. Since this was a unique study, it needs to be replicated to provide credibility and trustworthiness to its findings. It was the only study like it, so it needs further verification. Also, a similar study outside of the State of Utah would be a good complementary study to see how other areas of the United States and the world compare to the area studied here. Further, some mixed methods may be useful related to this topic. The researcher would recommend having nursing students assess their own risk of becoming addicted as nurses by employing quantitative methods of study. Then, they could be exposed to the stories and education by recovering nurse addicts discovered as a potential educational intervention in this study.

Finally, it may be beneficial to separate "nurse addicts" into more specific study groups in order to get more generalizable data. For instance, have a study only for nurses who used opiates from work, or have a study of nurses who did not become addicted until after becoming nurses or vice versa. Consider whether or not variables such as these are significant or predictive of high risk for addiction among nurses.

\section{Conclusions}

Substance abuse and addiction are serious concerns for the nursing profession. Nurses who have lived the nightmare of addiction have a keen insight into this phenomenon. Nurse addicts' lives are often filled with fear, guilt, and shame. Nurse addicts did not perceive themselves as being at risk for addiction. Most nurses do not consider themselves to be at risk for addiction, even with the presence of a strong family history of alcoholism or addiction. The knowledge and experience nurse addicts have and are willing to share could be very beneficial to nurses, and especially to occupational health nurses. It is no longer sufficient to just provide information about substance abuse. Understanding why nurses misuse substances and how they experience the different stages of addiction and recovery humanizes the experience, which may ultimately prevent other nurses from demonizing their colleagues who have this medical illness ${ }^{[4]}$. It could also help nurses realize their own risks for becoming addicted to drugs or alcohol, and this awareness may help nurses recognize what is happening early in the journey down the road to addiction and encourage entering treatment. Nurse educators are in a very important position for helping students, employees, peers, and co-workers.

\section{References}

[1] Copp, M.B. (2009). Drug addiction among nurses: confronting a quiet epidemic. Modern Medicine. Available from: http://www.modernmedicine.com/modernmedicine/Modern+Medicine+Now/Drug-addiction-among-nurses-Confronting-a-quiet-ep/Art icleStandard/ Article/detail/592623.

[2] Coleman, E.A., Honeycutt, G., Ogden, B., McMillan, D.E., O’Sullivan, P.S., Light, K. \& Wingfield, W. Assessing substance abuse among health care students and the efficacy of educational interventions. Journal of Professional Nursing. 1997; 13(1): 28-37. http://dx.doi.org/10.1016/S8755-7223(97)80024-5

[3] American Association of Colleges of Nursing [AACN]. Position statement: Policy and guidelines for prevention and management of substance abuse in the nursing education community. 1998; Available from: http://www.aacn.nche.edu/publications/position/substance-abuse- policy-and-guidelines.

[4] Dunn, D. Substance abuse among nurses—defining the issue. AORN. 2005; 82(4): 573-602. http://dx.doi.org/10.1016/S0001-2092(06)60028-8

[5] Donahue, P.M. Nursing: The finest art ( $3^{\text {rd }}$ ed.). St. Louis, MO: Elsevier, 2010.

Published by Sciedu Press 
[6] Clark, C., \& Farnsworth, J. Program for recovering nurses: an evaluation. MEDSURG Nursing. 2006; 15(4): $223-230$.

[7] Monroe, T. Addressing substance abuse among nursing students: development of a prototype alternative-to-dismissal policy. Journal of Nursing Education. 2009; 48(5): 272-278.

[8] Scimeca, P. D. Unbecoming a nurse: Bypassing the hidden chemical dependency trap. Staten Island, NY: Sea Meca, Inc, 2008.

[9] Ashworth, P. Presuppose nothing! The suspension of assumptions in phenomenological psychological methodology. Journal of Phenomenological Psychology. 1996; 27(1): 1-15. http://dx.doi.org/10.1163/156916296X00014

[10] Merriam, S.B. Qualitative Research: A Guide to Design and Implementation. San Francisco: Jossey-Bass, 2009.

[11] Creswell, J. W. Qualitative inquiry \& research design: choosing among five approaches (2nd ed.). Thousand Oaks, CA: Sage Publications, 2007.

[12] Mert, N. Fear culture II. International Journal of Learning \& Development. 2012; 2(2): 31-44. http://dx.doi.org/10.5296/ijld.v2i2.1547

[13] Peters, J., Kalivas, P. W. \& Quirk, G. J. Extinction circuits for fear and addiction overlap in prefrontal cortex. Learning \& Memory. 2009; 16(5): 279-288. http://dx.doi.org/10.1101/lm.1041309

[14] Goldstein, R. Z., Volkow, N. D., Chang, L., Wang, G., Fowler, J. S., Depue, R. A. \& Gur, R. C. The orbitofrontal cortex in methamphetamine addiction: Involvement in fear. Neuroreport: For Rapid Communication of Neuroscience Research. 2002; 13(17): 2253-2257. http://dx.doi.org/10.1097/00001756-200212030-00017

[15] American Psychiatric Association [APA]. Mental illness and drug addiction may co-occur due to disturbance in the brain's seat of anxiety and fear: Study finds rats with amygdalas damaged at birth showed abnormal adult behavior related to fear plus greater cocaine sensitivity. Washington, DC: American Psychological Association (APA), Public and Member Communications, Public Affairs Office, 2007.

[16] Mosavi Amiri, S. J. \& Homayouni, A. A. P03-240 - Psychological, environmental or physical factors, which is the first cause in tendency to addiction? European Psychiatry. 2010; 25: 1307. http://dx.doi.org/10.1016/S0924-9338(10)71294-3

[17] Wiklund, L. Existential aspects of living with addiction - Part I: Meeting challenges. Journal of Clinical Nursing. 2008; 17(18): 2426-2434. http://dx.doi.org/10.1111/j.1365-2702.2008.02356.x

[18] Gillespie, B.M., Chaboyer, W. \& Wallis, M. Development of a theoretically derived model of resilience through concept analysis. Contemporary Nurse. 2007; 25(1-2): 124-135. http://dx.doi.org/10.5172/conu.2007.25.1-2.124

[19] Pascual, A., Etxebarria, I. \& Cruz, M. Emotional differences between women with different types of eating disorders. International Journal of Psychology \& Psychological Therapy. 2011; 11(1): 1-11.

[20] Aven, T. On how to define, understand and describe risk. Reliability Engineering and System Safety. 2010; 95(6): 623-631. http://dx.doi.org/10.1016/j.ress.2010.01.011

[21] Hastings, J., \& Burn, J. Addiction: A nurse’s story. American Journal of Nursing. 2007; 107(8): 75-79. http://dx.doi.org/10.1097/01.NAJ.0000282301.11065.8e

[22] McCormick, L., \& Tompkins, N. O. Diffusion of CDC's guidelines to prevent tobacco use and addiction. Journal of School Health. 1998; 68(2): 43-45. http://dx.doi.org/10.1111/j.1746-1561.1998.tb07188.x

[23] Pirskanen, M., Pietilä, A., Halonen, P., \& Laukkanen, E. School health nurses and substance use among adolescents--towards individual identification and early intervention. Nordic College of Caring Science. 2006; 20(4): 439-447. http://dx.doi.org/10.1111/j.1471-6712.2006.00425.x

[24] Guidelines for school health programs to prevent tobacco use and addiction. Journal of School Health. 1994; 64(9): 353-359. http://dx.doi.org/10.1111/j.1746-1561.1994.tb06204.x

[25] Wood, T. K., Englander-Golden, P., Golden, D. E., \& Pillai, V. K. Improving addictions treatment outcomes by empowering self and others. International Journal of Mental Health Nursing. 2010; 19(5): 363-368.

http://dx.doi.org/10.1111/j.1447-0349.2010.00678.x

[26] White, W. L. Nonclinical addiction recovery support services: History, rationale, models, potentials, and pitfalls. Alcoholism Treatment Quarterly. 2010; 28(3): 256-272. http://dx.doi.org/10.1080/07347324.2010.488527

[27] Whitten, L. A brief encounter with peer educator can motivate abstinence. NIDA Notes. 2005; 20(3): 8-9.

[28] Villarosa, L. (2002, December 24). Recovering addicts help educate future doctors. New York Times, F6.

[29] McLellan, A. T., Lewis, D. C., O’Brien, C. P., \& Kleber, H. D. Drug dependence, a chronic medical illness: Implications for treatment, insurance, and outcomes evaluation. JAMA. 2000; 284(13): 1689-1695. http://dx.doi.org/10.1001/jama.284.13.1689

[30] National Institute on Drug Abuse [NIDA] (2007). Drug abuse prevention. A research update from the National Institute on Drug Abuse. Available from: http://drugabuse.gov/tib/prevention.html.

[31] Hyman, Z. Historical interpretations of alcohol use \& misuse implications for nursing curricula. Journal of Psychosocial Nursing. 2004; 42(11): 10. 